\title{
STRUČNO USAVRŠAVANJE VASPITAČA U OBLASTI INFORMACIONO-KOMUNIKACIONIH TEHNOLOGIJA
}

\author{
Dragana Pavlović ${ }^{1}$, \\ Univerzitet u Nišu, Filozofski fakultet u Nišu, Departman za \\ komunikologiju i novinarstvo \\ Zorica Stanisavljević Petrović \\ Univerzitet u Nišu, Filozofski fakultet u Nišu, Departman za pedagogiju
}

\begin{abstract}
Apstrakt: U radu se razmatraju pitanja vezana za stručno usavršavanje vaspitača predškolskih ustanova u oblasti informaciono-komunikacionih tehnologija. Centralni deo rada posvećen je obrazovnim potrebama vaspitača, koje se razvijaju u skladu sa opštim društvenim promenama. U skladu sa menjanjem društva i razvojem savremenih informaciono -komunikacionih sredstva potencira se pitanje kompetencija vaspitača za primenu novih medijskih sredstva u radu sa decom. Analiza dosadašnjih istraživanja ide u prilog stavu da vaspitači nisu u dovoljnoj meri pripremljeni za korišćenje savremenih medijskih načina komunikciranja i da je to jedan od glavnih razloga nedovoljne primene $u$ radu. Kao preporuka izdavaja se potreba za sistematskim i planskim razvojem informaciono-komunikacionih kompetencija vaspitača.
\end{abstract}

Ključne reči: informaciono-komunikacione tehnologije, obrazovne potrebe, stručno usavršavanje, vaspitači.

\section{Uvod}

Promene u savremenom društvu u značajnoj meri uslovljene su razvojem savremenih infromaciono-komunikacionih tehnologija. Ubrzani razvoj savremenih tehnologija značajno je uticao na promene u oblasti obrazovanja na svim novioma, počev od predškolskog do univerzitetskog obrazovanja. Sve veće prisustvo medijskih tehnologija u svim segmentima života i rada savremenog čoveka dovelo je do izjednačavanja važnosti opšte i informatičke pismenosti. Shodno tome, u razvijenim zemljama sveta prepoznata je potreba za razvojem informatičke pismenosti,

\footnotetext{
${ }^{1}$ dragana.pavlovic@filozofski.rs
} 
kao prioriteta sa kojim treba krenuti još od najranijeg uzrasta (Dezuanni et al., 2015; Zevenbergen \& Logan, 2008). U skladu sa tim, u većem broju razvijenih zemalja se sa informatičkim opismenjavanjem kreće na nivou predškolskog obrazovanja. Deca ranog uzrasta, veoma rado prihvataju nove tehnologije, sa kojima se sreću tokom odrastanja još u porodičnom okruženju. Iskustva dece sa tehnologijama se prenose $\mathrm{u}$ predškolske ustanove u kojima vaspitači planski i sistematski uvode decu u svet informatičke pismenosti i komunikacija. Na taj način informatičko obarazovanje postaje jedan od ciljeva u radu sa decom, za čiju realizaciju su zaduženi vaspitači predškolskih ustanova. Uloga vaspitača, kao kreatora i moderatora neposrednog rada sa decom ranog uzrasta sada dobija nove dimenzije, koje se baziraju na aktivnom korišćenju sredstava novih informaciono-komunikacionih tehnologija. U skladu sa tim, pred vaspitačima stoje novi izazovi i očekivanja, koji uslovljavaju nove obrazovne potrebe. Naime, od vaspitača se očekuje razvijen nivo korišćenja savremenih informaciono-komunikacionih tehnologija, kao i uvođenje dece u svet medijskih alata koji su neophodni za dalje obrazovanje i život u modernom društvu. Međutim, $u$ istraživanjima na našem području dokazano je da razvoj kompetencija vaspitača u delu primene savremenih medijskih tehnologija nije na zavidnom nivou, što potencira potrebu za dodatnim stručnim usavršavanjem u ovoj oblasti (Arsenijević i Andevski, 2011; Anđelić i Milosavljević, 2007).

\section{Informaciono-komunikacione tehnologije i obrazovne potrebe vaspitača}

Brz i intenzivan razvoj novih informaciono-komunikacionih tehnologija bitno je uticao na oblast obrazovanja na svim nivoima, od predškolskog do visokoškolskog nivoa. Pod uticajem ovih sredstva bitno je promenjen profil obrazovanja, pre svega u smislu metoda rada, koje postaju savremenije i primerenije uzrastu dece. Sredstva novih medijskih tehnologija su sastavni deo života dece ranog uzrasta od porodičnog okruženja pa do institucija obrazovanja (Plowman \& McPake, 2013). Pojavom računara, a pre svega interneta, predškolsko vaspitanje dobija nove dimenzije, novi kvalitet saobražen potrebama savremenog društva. Internet je umnogome uticao da se prevaziđu klasični načini rada sa decom, što je i sastavni deo izazova koje nose nove reforme obrazovnog sistema. Primenom savremenih informacionokomunikacionih alata rad vaspitača u predškolskim ustanovama postao je bogatiji i savremeniji, jer ova sredstva imaju značajne potencijale za unapređivanje kvaliteta (Lindahl \& Folkesson, 2012; Siraj-Blatchford et al., 2008). U referentnoj literaturi sve veća pažnja posvećuje se sredstvima novih tehnologija i njihovom uticaju na različite aspekte ličnosti deteta (Radesky et al., 2015; Kirkorian et al., 2008). Upotreba interneta, kao i pratećih medijskih alata stvorila je novu osnovu za rad vaspitača, jer su mnoge informacije postale dostupne i povećana je mogućnost razmene iskustva putem blogova koje vode sami vaspitači. Razmena informacija i brža i efikasnija komunikacija prisutna je i u delu saradnje sa roditeljima, koji sada imaju 
mogućnost da pravovremeno dobiju informacije o svom detetu i o mogućnostima uključivanja u rad ustanove. U tom delu, saradnja sa roditeljima postaje intenzivnija i funkcionalnija, primerenija savremenim roditeljima koji i sami koriste sredstva savremenih komunikacionih tehnologija (Thompson, 2008). Ipak, čini se da su se najznačajnije promene desile u obrazovnom radu, koji je obogaćen novim medijskim alatima koji obrazovanje dece ranog uzrasta čine efikasnijim, jer raspolažu značajnim edukativnim potencijalima. U prilog tome navode se brojna istraživanja koja ukazuju na pozitivne efekte primene obrazovnih softvera, interaktivnih tabli, mobilnih uređaja, računarskih igara i igračaka posebno dizajniranih za decu ranog uzrasta (Gnjatović, 2015; Ayvac1 \& Devecioğlu, 2010). Autori posebno ukazuju na benefite u kognitivnom razvoju koji su vezani za primenu obrazovnih softvera u ranom obrazovanju, posebno u delu motivacije za učenje i boljeg usvajanja i trajnosti funkcionalnih znanja (Vernadakis et al., 2005). Nasuprot shvatanju da se sredstva informaciono-komunikacionih tehnologija mogu negativno odraziti na dečiji razvoj, sve je veći broj istraživanja u praksi, u kojima se potvrđuje pozitivno delovanje tehnologije na socijalni, emocionalni i intelektualni razvoj dece predškolskog uzrasta (Granic et al., 2014; Strasburger et al., 2009). Istraživanja takođe beleže da adekvatna i pravovremena primena medijskih sredstava $u$ ranom detinjstvu stvara dobru osnovu za pravilan odnos dece prema sredstvima tehnologije, u smislu rukovanja, ali i boljeg razumevanja (Stanisavljević Petrović i Pavlović, 2017). U skladu sa takvim nalazima veoma je važno da se deci od ranog uzrasta omogući jednak pristup informaciono-komunikacionim tehnologijama, posebno računarima, jer je pravo deteta da stiče bogata i raznovrsna iskustva sa tehnologijama u okruženju. Sve to naravno zahteva i adekvatna finansijska ulaganja u opremanje predškolskih ustanova i razvoj infrastrukture (hardver, softver, mreža), ali i kvalitetnije pripremanje i stručno usavršavanje vaspitača (Anđelković, 2008).

Posmatrano sa tog stanovišta veoma je važno definisati obrazovne potrebe, posebno u delu informaciono-komunikacionih tehnologija. U sistemu predškolskog vaspitanja u Srbiji obrazovne potrebe vaspitača su stavljene u prvi plan i one proizlaze iz njihove želje da što profesionalnije obave svoj posao i unaprede razvoj deteta. U skladu sa tim, u sistemu stručnog usavršavanja cilj nije samo sakupljanje bodova o pohađanim programima stručnog usavršavanja i dobijanje licence za rad, već su razlozi za stručno usavršavanje mnogo dublji i proizlaze iz želje za nadograđivanjem sebe kao jedinke koja je spremna da izađe u susret izazovima koje nose savremene informaciono-komunikacione tehnologije. Sa ciljem da pruže kvalitetnu uslugu i da zadovolje potrebe dece, vaspitači se suočavaju sa izazovima pri izboru odgovarajućih pedagoških i metodoloških pristupa, kao i pri izboru adekvatnih medijskih sredstava.

U svetlu savremenih pogleda na pedagošku praksu, pristup novim tehnologijama treba bude baziran na igri, sa detetom u centru pažnje. U isto vreme, vaspitač je aktivni posmatrač koji treba da ohrabruje decu za primenu informaciono-komunikacionih tehnologija koje stimulišu njihov razvoj. Različite teorije razvoja deteta, poput kognitivne, bihejvioralne i sociokulturne teorije, daju širok opseg pristupa i definicija koje mogu biti od pomoći vaspitačima u razumevanju dečijeg 
ponašanja i njihovih razvojnih sposobnosti (Gnjatović, 2015). Pored toga, savremene teorije učenja, pre svega konstruktivistička, a u novije vreme i konekstivistička teorija, sve više naglašavaju potencijale tehnologija za razvoj sposobnosti, znanja i veština dece.

Pitanje stručnog usavršavanja vaspitača u oblasti infromaciono-komunikacionih tehnologija je veoma kompleksno pitanje koje zahteva planski pristup. Shodno tome, planiranje stručnog usavršavanja vaspitača je važan i neophodan uslov stručnog napredovanja kao i neophodan aspekt adekvatnog funkcionisanja predškolske ustanove. Prvi korak u realizaciji planskog pristupa je utvrđivanje obrazovnih potreba vaspitača u domenu informaciono-komunikacionih tehnologija. Utvrđivanje obrazovnih potreba vaspitača mora da bude u skladu sa potrebama savremenog doba, novih izazova i problema, kao i upotrebe savremenih metoda za rad, što je u uskoj vezi sa upotrebom savremenih tehnologija. Novonastalim potrebama vaspitača nije dovoljno redovno školovanje na kojem se stiču osnovna i napredna znanja iz informaciono-komunikacione oblasti, već je tokom života neophodno pratiti sva nova dostignuća (Soleša Grijak i Soleša, 2011). To je posebno važno jer se informaciono-komunikacione tehnologije brzo razvijaju, a postojeći medijski alati stalno inoviraju.U tom kontekstu stalno stručno usavršavanje vaspitača u oblasti informaciono-komunikacionih tehnologija je neophodnost za kvalitetan rad vaspitača. Bez permanentnog stručnog usavršavanja u domenu savremenih komunikacionih sredstava vaspitač neće moći da održi i unapredi kvalitet spostvenog rada.

Značajna podrška vaspitačima na putu profesionalnog razvoja su raznovrsni oblici usavršavanja poput stručnih seminara, kongresa, naučnih skupova i drugih oblika usavršavanja koji su zastupljani u dosadašnjoj praksi. Učešće vaspitača u ovim oblicima je dalo izvesne rezultate, ali je svakako pored toga neophodno imati u vidu da se stručnom usavršavanju mora pristupiti sistematski. Sistematski pristup podrazumeva mnogo ozbiljnije angažovanje vaspitača od posećivanja seminara koji se održavaju nekoliko puta godišnje ili manje. U tom kontekstu sredstva savremene informaciono-komunikacione tehnologije pružaju mogućnost da vaspitači prate najsavremenija saznanja iz sveta, putem učešća na webminarima (seminarima koji se realizuju elektronskim putem).

Da bi se vaspitači uopšte uključili u proces usavršavanja u oblasti informaciono-komunikacionih tehnologija neophodno je da i sami budu svesni svojih znanja i veština u ovoj oblasti. Za to je potrebna visoka samosvest vaspitača o kompetencijama kojima raspolažu (Pavlović i Mihajlov-Prokopović, 2015). U svakom slučaju vaspitači treba da uzmu aktivniju ulogu u delu stručnog usaršavanja u oblasti novih medijskih tehnologija, upravo koristeći sve izvore koji mogu biti od koristi, pre svega mogućnosti usavršavanja preko stručne literature koja je u značajnoj meri dostupna i webminara koji se redovno organizuju.

Stručno usavršavanje vaspitača u oblasti infroamciono-komunikacionih tehnologija postaje sve neophodnije, jer sa pojavom interneta i drugih sredstva informacione tehnologije i njihovim zalaženjem u oblast predškolstva, uloge vaspitača značajno postaju složenije. Uloga vaspitača sama po sebi je veoma složena, a pojavom 
interneta ona postaje još kompleksnija. Savremena pedagoška praksa od vaspitača očekuje da prate napredovanja u oblasti informacionih tehnologija, a da ih zatim uvode u vaspitno-obrazovni rad Anđelković (2008). Ističe, međutim, i saznanje da je od izuzetne je važnosti da su današnja deca već duboko zakoračila u svet inforamacione tehnologije, te da i oni koji se bave njihovim vaspitanjem i obrazovanjem treba snažnije da krenu u proširivanje svojih znanja u ovoj oblasti. Dakle, od velike je važnosti da vaspitač unapređuje i razvija svoje veštine koje se odnose na primenu interneta i drugih informacionih tehnologija u radu sa predškolskom decom.

Da bi bio adekvatno osposobljen i edukovan za primenu interneta, vaspitač treba da posećuje razne seminare vezane za ovu temu, da poseduje računar u radnoj sobi, u svom domu, da samoinicijativno proširuje svoja znanja i veštine. Neophodno je da vaspitač poznaje osnovne programe kao što su Word, Exel, Power Point, programe koji se odnose na rad sa decom predškolskog uzrasta. Pored adekvatne osposobljenosti za primenu interneta u radu sa predškolskom decom, neophodno je da vaspitač stečena znanja kreativno i stvaralački koristi, da u svakom trenutku zna koji je najprikladniji način da privuče pažnju dece i proces podučavanja učini zanimljivijim.

Vaspitač mora biti spreman na to da njegovo usavršavanje traje koliko i njegov radni vek. Dakle, sa daljim razvojem informacionih tehnologija, uloge vaspitača i zahtevi koji se pred njih stavljaju značajno će se usložnjavati. Iz tog razloga, neophodno je da vaspitači izlaze u susret promenama koje sa sobom nosi informaciona tehnologija, kako bi mogli ići u korak sa njenim ubrzanim razvojem.

\section{Kompetencije vaspitača u oblasti infromaciono-komunikacionih tehnologija}

Uloga vaspitača u vaspitno-obrazovnom procesu je veoma složena i kompleksna i zahteva posedovanje određenih kompetencija. Osim svojih uobičajenih uloga (uloga organizatora fizičke sredine, uloga medijatora, pomoćnika...), vaspitač mora razvijati svoje kompetencije kao istraživač, što znači da je potrebno da blagovremeno nauči kako i na koji način može prikupljati, skladištiti i koristiti informacije kako bi unapredio sopstvenu praksu. U tom pogledu značajnu pomoć nude sredstva informaciono-komunikacionih tehnologija koje omogućavaju da vaspitač brzo i lako dođe do željenih informacija, da razmeni iskustva sa kolegama, da obogati vaspitni rad sa decom i ima efikasnu komunikaciju sa roditeljima. Da bi mogao da koristi bogatu paletu medijskih sredstava, potrebno je da vaspitač ima razvijene informaciono-komunikacione kompetencije, odnosno razvijene sposobnosti i veštine za adekvatno rukovanje savremenim medijima (Anđelić i Milosavljević, 2007). Kompetencije vaspitača u oblasti informaciono-komunikacionih tehnologija danas više nisu stvar izbora, već neophodnost. Smatra se da pored pedagoške intuicije, senzibilnosti, fleksibilnosti, odgovornosti, kreataivnosti, računarska pismenost predstavlja kvalitet koji mora posedovati jedan vaspitač (Tomić i Duković, 2008). U skladu sa tim, po- 
drazumeva se da vaspitači u svom radu moraju koristiti računar i raznovrsne računarske programe. Osim toga, oni mogu i moraju biti kreatori obrazovnih računarskih programa - razvojno-adekvatnih softvera, jer jedino oni imaju praktično iskustvo u radu sa decom. Naravno, samo kreiranje softvera mogu samostalno realizovati u domenu svojih znanja, dok složenije aspekte treba prepustiti stručnjacima iz oblasti informacionih tehnologija.

Pitanje adekvatnih kompetencija vaspitača u oblasti informaciono-komunikacionih tehnologija poslednjih decenija izaziva veliku pažnju istraživača. Neki autori smatraju da je neophodno vaspitače obučiti putem specifičnih edukacija koje bi im omogućile da savremena medijska sredstva koriste na najbolji mogući način (Janković i Dmitrić, 2011). U prilog tome navodi se da specifična edukacija treba da vaspitačima omogući ovladavanje onim infromaciono-komunikacionim tehnologijama koje su im neophodne u radu. U prilog tome Anđelković (2008: 75) navodi neophodni nivo kompetncija za realizaciju vaspitno-obrazovnh aktivnosti sa predškolskom decom:

- posedovanje osnovnih informatičkih znanja i veština;

- ovladavanje specifičnim informatičkim znanjima koja se odnose na rad sa predškolskom decom;

- upotreba štampača, skenera, kamere, itd.;

- ovladavanje programima koji se mogu iskoristiti za rad sa decom;

- upoznavanje sa pozitivnim i negativnim uticajima medijskih tehnologija na pojedina područja dečijeg razvoja.

Slično tome i drugi autori smatraju da razvoj informatičkih kompetencija postavlja nove zahteve pred vaspitača: izgradnja i jačanje stručne i pedagoško-metodičke kompetencije za upotrebu novih informacionih tehnologija (Veličković, 2014).

Potrebno je imati u vidu da vaspitači predstavljaju jednu heterogenu strukturu, da se međusobno razlikuju prema interesovanju i kompetencijama za primenu informaciono-komunikacionih sredstava. Starije generacije vaspitača karakteriše manja upotreba računara i interneta. Takva situacija se najčešće objašnjava time da stariji vaspitači u toku svog školovanja nisu osposobljavani za primenu ovih sredstava informacione tehnologije. Međutim, nove generacije vaspitača dolaze, delimično ili potpuno, spremne da na pravilan način upute decu u svet računara i interneta koji postaju njihovi svakodnevni pratioci (Veličković, 2014). Poslednjih godina sve veća pažnja se poklanja edukaciji budućih vaspitača u pravcu uvođenja informacionih tehnologija u obrazovni sistem. Na Visokim školama strukovnih studija za obrazovanje vaspitača i na učiteljskim fakultetima, realizuju se programi predmeta iz oblasti informacionih tehnologija, koji podrazumevaju sticanje znanja na korisničkom nivou (operativni sistem, internet, program za obradu teksta, program za crtanje, program za pravljenje prezentacije, obrada zvuka i videa, upoznavanje sa gotovim edukativnim softverima: CD-bukvar....) u okviru jednog ili više predmeta. Međutim, ako se ima u vidu brz razvoj informaciono-komunikacionih sredstava, samo školovanje ipak nije dovoljno, već je potrebno stručno usavršavanje. 
Profesionalne kompetencije vaspitača za primenu interneta i drugih informacionih tehnologija u radu sa decom predškolskog uzrasta zahtevaju kontinuirano usavršavanje vaspitača kroz različite oblike edukacije: kursevi informatike, seminari iz ovih oblasti, različiti sajtovi, a sve je više na tržištu i stručne literature na temu informatičkog obrazovanja (Veličković i Stošić, 2016). Za edukaciju vaspitača postoje i specijalizovani sajtovi koji omogućavaju dodatna usavršavanja vaspitača u oblasti informaciono-komunikacionih tehnologija. Krajnji cilj ovih edukacija je osposoblajavanje vaspitača za primereno korišćenje novih informaciono-komunikacionih tehnologija, posebno računara. Da bi vaspitač u vaspitno-obrazovnom radu sa decom koristio računar i internet, neophodno je da poseduje stručne kompetencije koje obuhvataju znanja i sposobnosti potrebne za primenu ovih tehnologija (Pavlović et al., 2016; Arsenijević i Andevski, 2011). Pored toga, naravno potrebno je da vaspitač poseduje i razvijene pedagoško-metodičke kompetencije, koje podrazumevaju adekvatnu upotrebu informaciono-komunikacione tehnologije u radu sa decom (Veličković, 2014). U edukaciju vaspitača spada i zadatak vaspitača da kod dece razvije veštine potrebne za upotrebu interneta i drugih informacionih tehnologija, kao i da informacionu tehnologiju primenjuje u didaktičke svrhe u svakodnevnom vaspitno-obrazovnom radu, tj. da je integriše u svakodnevnu praksu. Veoma je važno da vaspitači uvide obrazovni značaj interneta za celokupan razvoj predškolske dece, kao i činjenicu da njegova upotreba doprinosi povećanju kvaliteta i efikasnosti svih segmenata vaspitno-obrazovnog procesa i njihove lične prakse (Arsenijević i Andevski, 2012). Primena interneta i drugih informacionih tehnologija je značajan preduslov uspešnog dečjeg razvoja, pa je upravo uloga vaspitača, kao vodećeg kreatora vaspitno-obrazovnog procesa u svemu tome od neprocenjivog značaja.

\section{Zaključak}

Proces informatizacije koji značajno utiče na oblikovanje savremenog društva i život modernog čoveka nesumnjivo je zahvatio i oblast obrazovanja. Na svim nivoima školskog sitema došlo je do promena nastalih implementacijom savremenih informaciono-komunikacionih tehnologija. Shodno tome, primena savremenih medijskih sredstva postala je sastavni deo obrazovnog procesa od predškolskog do visokoškolskog obrazovanja. U procesu implementacije informaciono-komunikacione tehnologije na prvom stupnju obrazovanja, značajnu ulogu imaju vaspitači, kao nosioci i kreatori vaspitno-obrazovnog rada sa najmlađima.

Pod uticajem savremenih informaciono-komunikacionih tehnologija došlo je do značajnih promena u radu i ulogama vaspitača predškolskih ustanova. Naime, pored stalnih i odgovornih uloga razvile su se nove, koje podrazumevaju posedovanje informatičkih kompetencija. Za profesiju vaspitača posedovanje ovih komptencija je posebno značajno, jer su oni, zajedno sa roditeljima, prvi medijatori između dece ranog uzrasta i savremenih medijskih tehnologija. U tom kontekstu, sve su izraženiji zahtevi za razvoj informaciono-komunikacionih kompetencija vaspitača, pre svega u domenu korišćenja u radu sa decom. Ovi zahtevi odražavaju se na strukturu pro- 
grama za obrazovanje vaspitača, u kojima sve veći udeo pripada nastavnim predmetima koji se bave sredstvima savremenih tehnologija. Međutim, ma koliko bilo inovirano, obrazovanje vaspitača predškolskih ustanova svakako nije dovoljno, jer se rađaju nove obrazovne potrebe koje je moguće zadovoljiti samo dodatnim stručnim usavršavanjem. Iz tog razloga dodatno stručno usavršavanje vaspitača ima sve veći značaj, posebno kada je reč o savremenim informacionim sredstvima koja se razvijaju velikom brzinom i intenzitetom. Premda je za sada stručno usavršavanje vaspitača znatno napredovalo u odnosu na prethodne decenije, ipak i dalje postoji potreba za razvojem kompetencija i usavršavanjem u oblasti novih medijskih tehnologija.

Poslednjih godina sve veća pažnja se poklanja edukaciji budućih vaspitača u pravcu uvođenja informacionih tehnologija u obrazovni sistem, mada svi dosadašnji napori još uvek nisu zadovoljavajući. U praksi predškolstva još uvek postoje veliki problemi vezani pre svega za nedovoljnu opremljenost predškolskih ustanova sredstvima informaciono-komunikacionih tehnologija. Pored toga, kao značajan problem izdvajaju se kompetencije vaspitača u ovoj oblasti, koje nisu na zadovoljavajućem nivou. Za rešavanje ovih problema neophodno je sistematsko i plansko delovanje na planu osmišljavanja adekvatnih načina i oblika stručnog usavršavanja vaspitača, uz angažovanje svih aktera zaduženih za unapređivanje kvaliteta u obrazovanju.

\section{Literatura}

Anđelić, S. i Milosavljević, G. (2007). Nove informacione tehnologije u obrazovanju dece. INFOTEH - Jahorina. 6 (Ref. E-IV-8), 494-498.

Anđelković, N. (2008). Dete i računar u porodici i dečjem vrtiću. Beograd: Beoknjiga i Savez informatičara Vojvodine.

Arsenijević, J. i Andevski, M. (2012). Novi mediji kao pravac razvoja kompetencija zaposlenih u predškolskom obrazovanju. Kultura, 135, 28-48.

Arsenijević, J. i Andevski, M. (2011). Kompetencije vaspitača za upotrebu novih medija i tehnologija. Zbornik VŚSSOV Kikinda, 4(2), 25-34.

Ayvacı, H. S. \& Devecioğlu, Y. (2010). Computer-assisted instruction to teach concepts in pre-school education. Procedia-Social and Behavioral Science, 2(2), 2083-2087.

Dezuanni, M., Dooley, K., Gattenhof, S. \& Knight, L. (2015). IPads in the Early Years: Developing Literacy and Creativity. Abington: Routledge

Gnjatović, D. (2015). Priče u različitim domenima dečjeg razvoja. Istraživanja u pedagogiji, 5(1), 81-93.

Granic, I., Lobel, A. \& Engels, R. C. M. E. (2014). The benefits of playing video games. American Psychologist, 69(1), 66-78.

Janković, M. i Dmitrić, Lj. (2011). Primena računara u pripremnom predškolskom programu. U D. Golubović (ur.). TIO Tehnologija, informatika i obrazovanje za društvo učenja i znanja. Čačak: Tehnički fakultet. Preuzeto sa http://www.ftn.kg.ac.rs/konferencije/tio6/radovi/3)\%20Nastavnici\%20i\%20skola\%20u\%20informaciono-tehnoloskom\%20okruzenju/PDF/304\%20Marina\%20Jankovic.pdf 
Kirkorian, H. L., Wartella, E. A. \& Anderson, D. R. (2008). Media and Young Children's Learning. The Future of Children, 18(1), 39-61.

Lindahl, M. G. \& Folkesson, A. M. (2012). ICT in preschool: friend or foe? The significance of norms in a changing practice. International Journal of Early Years Education, 20(4), 422-436.

Pavlovic, D., Stanisavljevic Petrovic, Z. \& Soler-Adillon, J. (2016). Traditional and (or) new media: Teachers' work experience and aplication of media in schools. eLearning vision 2020, 2, 182-187.

Pavlović, D. \& Mihajlov-Prokopović, A. (2015). Attitudes of teachers to the application of computers in preschools. Rethinking education by leveraging the eLearning pillar of the Digital Agenda for Europe, 1, 211-283.

Plowman, L. \& McPake, J. (2013). Seven Myths About Young Children and Technology. Childhood Education, 89(1), 27-33.

Radesky, J. S., Schumacher, J. \& Zuckerman, B. (2015). Mobile and Interactive Media Use by Young Children: The Good, the Bad, and the Unknown. Pediatrics, 135(1), $1-4$.

Siraj-Blatchford, I., Taggart, B., Sylva, K., Sammons, P. \& Melhuish, E. (2008). Towards the transformation of practice in early childhood education: the effective provision of pre-school education (EPPE). Cambridge Journal of Education, 38(1), 23-36.

Soleša Grijak, Đ. i Soleša, D. (2011). Kompetentnost predškolskih vaspitača za društvo učenja. Pedagogija, 66(4), 648-655.

Stanisavljević Petrović, Z. i Pavlović, D. (2017). Novi mediji u ranom obrazovanju. Niš: Filozofski fakultet.

Strasburger, V. C., Wilson, B. J. \& Jordan, A. B. (2009). Children, Adolescents, and the Media. Washingron, DC: Sage.

Thompson, B. (2008). Characteristics of Parent-Teacher E-Mail Communication. Communication Education, 57(2), 201-223.

Tomić, I. i Duković, Z. (2008). Obrazovni softver u obrazovanju. Kruševac: Visoka škola za obrazovanje vaspitača u Kruševcu.

Veličković, S. (2014). Edukacija vaspitača za primenu IKT u vrtiću. Sinteza - Međunarodna konferencija Univerziteta Singidunum, 41 (2), 375-378.

Veličković, S. \& Stošić, L. (2016). Preparedness of educators to implement modern information technologies in their work with preschool children. International Journal of Cognitive Research in Science, Engineering and Education / IJCRSEE, 4(1), 23-30.

Vernadakis, N., Avgerinos, A., Tsitskari, E. \& Zachopoulou, E. (2005). The Use of Computer Assisted Instruction in Preschool Education: Making Teaching Meaningful. Early Childhood Education Journal, 33(2), 99-104.

Zevenbergen, R. \& Logan, H. (2008). Computer use by preschool children: rethinking practice as digital natives comes to preschool [online]. Australian Journal of Early Childhood, 33(1), 37-44. 


\title{
PROFESSIONAL DEVELOPMENT OF PRESCHOOL TEACHERS IN THE FIELD OF INFORMATION AND COMMUNICATION TECHNOLOGIES
}

\author{
Dragana Pavlović, \\ University of Niš, Faculty of Philosophy, Niš, Department of Communicology \\ and Journalism \\ Zorica Stanisavljević Petrović \\ University of Niš, Faculty of Philosophy, Niš, Department of Pedagogy
}

\begin{abstract}
The paper deals with issues related to the professional development of preschool teachers in the field of information and communication technologies. The central part of the paper is dedicated to the educational needs of preschool teachers, which are developing in accordance with the general social changes. In line with the changing society and the development of modern information and communication resources, the question of the preschool teachers' competencies for the application of new media resources in working with children is being emphasized. The analysis of previous research supports the view that preschool teachers are not sufficiently prepared for use of modern media communication methods and that this is one of the main reasons for their insufficient application in work. As a recommendation, the need for systematic and planned development of information and communication competences of preschool teachers is emphasized.
\end{abstract}

Key Words: information and communication technologies, educational needs, professional development, preschool teachers.

\section{Citiranje članka:}

Pavlović, D. i Stanisavljević Petrović, Z. (2017). Stručno usavršavanje vaspitača u oblasti informaciono-komunikacionih tehnologija. Godišnjak za pedagogiju, 2(1), 21-30. 